\title{
A Case of Congenital Common Bile Duct Web Treated with Balloon Dilation under Endoscopic Retrograde Cholangiopancreatography in a Young Child
}

\author{
Ji Sook Park ${ }^{1,2}$, Hong Jun Kim ${ }^{2,3}$, Ji-Hyun Seo ${ }^{1,2}$ and Hee-Shang Youn ${ }^{1,2}$ \\ ${ }^{1}$ Department of Pediatrics, Gyeongsang National University Hospital and Gyeongsang National University School of Medicine, ${ }^{2}$ Institute \\ of Health Sciences, Gyeongsang National University, ${ }^{3}$ Department of Internal Medicine, Gyeongsang National University Hospital and \\ Gyeongsang National University School of Medicine, Jinju, Korea
}

Web in common bile duct (CBD web) is very rare. It is usually asymptomatic and detected incidentally during surgery for other causes in adults. It can be congenital or acquired, however congenital CBD web is extremely rare. Currently, despite its invasiveness and complications, endoscopic retrograde cholangiopancreatography (ERCP) is considered as a useful diagnostic and therapeutic modality in children with hepatobiliary pancreatic diseases as in adults. Herein we report a case of congenital CBD web presenting with acute pancreatitis and choledocholithiasis in a 4-year-old girl which was diagnosed and treated using balloon dilation under ERCP. After balloon dilation of the web, a common pancreatobiliary channel was observed. To the best of our knowledge, a case of congenital CBD web with pancreatobiliary junctional abnormality treated using ERCP in a child has not been reported to date. Clin Endosc 2021;54:285-288

Key Words: Common bile duct; Congenital; Endoscopic retrograde cholangiopancreatography; Web

\section{INTRODUCTION}

Extrahepatic biliary obstruction is often caused by a common bile duct (CBD) stone, a benign or malignant biliary stricture in adults ${ }^{1}$; however, in children more diverse factors such as primary biliary cholangitis, post-liver transplantation, extrahepatic biliary atresia, and choledochal cyst are involved. ${ }^{2,3} \mathrm{CBD}$ stone may cause extrahepatic biliary obstruction in children, but it is uncommon. In addition, congenital CBD web is an extremely rare cause of extrahepatic biliary

Received: June 16, 2020 Revised: June 30, 2020

Accepted: July 1, 2020

Correspondence: Ji-Hyun Seo

Department of Pediatrics, Gyeongsang National University Hospital and Gyeongsang National University School of Medicine, 15 Jinju-daero 816 beon-gil, Jinju 52727, Korea

Tel: +82-55-750-8161, Fax: +82-55-752-9339, E-mail: seozee@gnu.ac.kr ORCID: https://orcid.org/0000-0002-0691-3957

(c) This is an Open Access article distributed under the terms of the Creative Commons Attribution Non-Commercial License (http://creativecommons.org/ licenses/by-nc/3.0) which permits unrestricted non-commercial use, distribution, and reproduction in any medium, provided the original work is properly cited. obstruction. ${ }^{4}$

Endoscopic retrograde cholangiopancreatography (ERCP) is widely used as a diagnostic and therapeutic modality for pancreaticobiliary disease (PBD) in adults. ERCP was less commonly performed in children because of the lower incidence of PBD in children than in adults; furthermore, the invasiveness nature of the procedure and the associated complications rendered it less suitable for children. ${ }^{3}$ However, the effectiveness of ERCP in the management of pediatric PBD has been reported recently. ${ }^{5-9}$

A small number of congenital biliary web cases in infants and children has been reported worldwide. ${ }^{4}$ However, to the best of our knowledge, a case of congenital web of the CBD in a child treated with balloon dilation under ERCP has not yet been reported. Herein, we report a case of congenital CBD web diagnosed and treated with ERCP in a previously healthy 4-year-old girl.

This case report was reviewed and approved by the International Review Board of Gyeongsang National University Hospital (GNUH 2020-03-005). 


\section{CASE REPORT}

A 4-year-old girl visited our hospital because of colicky abdominal pain. The patient complained of abdominal pain 1 day ago. The pain was throbbing and localized in the periumbilical area. She refused to eat her meal due to aggravation of the abdominal pain and was seldom able to move. Fever, vomiting, or diarrhea was absent. Furthermore, no history of previous medical problem, surgery, or abdominal trauma was present. The mother had several silent stones in the gallbladder (GB), which were detected during routine health checkup.

The patient's weight and height were $18 \mathrm{~kg}$ (50-75th percentile) and $103.1 \mathrm{~cm}$ (50-75th percentile), respectively. Vital signs were relatively stable, with a blood pressure of $100 / 70 \mathrm{~mm} \mathrm{Hg}$, heart rate of 104 beats/min, respiratory rate of 28 breaths $/ \mathrm{min}$, and body temperature of $36.5^{\circ} \mathrm{C}$. Physical examination revealed decreased bowel sound and abdominal tenderness on the periumbilical area.

The hemoglobin, white blood cell, and platelet counts were $13.1 \mathrm{~g} / \mathrm{dL}, 8,210 / \mathrm{mm}^{3}$, and $310 \times 10^{6} / \mathrm{mm}^{3}$, respectively.
Hemolysis was not noted. Blood chemistries were as follows: cholesterol $157 \mathrm{mg} / \mathrm{dL}$ (reference range, 120-200 mg/dL), total protein $7.9 \mathrm{mg} / \mathrm{dL}(6.1-7.9 \mathrm{mg} / \mathrm{dL})$, albumin $4.9 \mathrm{mg} /$ dL (3.5-5.6 mg/dL), alkaline phosphatase $294 \mathrm{U} / \mathrm{L}$ (134-386 $\mathrm{U} / \mathrm{L}$ ), aspartate aminotransferase (AST) $271 \mathrm{U} / \mathrm{L}$ (15-40 U/ L), alanine aminotransferase level (ALT) $115 \mathrm{U} / \mathrm{L}$ (5-45 U/ L), gamma glutamyl transpeptidase (GGT) $202 \mathrm{U} / \mathrm{L}$ (5-32 U/ L), total bilirubin $0.63 \mathrm{mg} / \mathrm{dL}(<2.0 \mathrm{mg} / \mathrm{dL}$ ), amylase $320 \mathrm{U} / \mathrm{L}$ (16-91 U/L), and lipase of $567 \mathrm{mg} / \mathrm{dL}$ (4-29 mg/dL).

Abdominal X-ray showed focal ileus in the central part of the abdomen. Abdominal ultrasonography (USG) revealed a swollen pancreas, dilated intrahepatic bile duct, and a CBD $0.94 \mathrm{~cm}$ in diameter and a $4.7-\mathrm{mm}$-sized echogenic focus in the distal CBD (Fig. 1A, B). The echogenic focus was suggested to be a CBD stone without posterior shadow. A septum in the $\mathrm{CBD}$ was noted on the coronal view of pancreaticobiliary computed tomography (CT; Fig. 1C). Acute pancreatitis, with biliary obstruction due to the stone and web-like structure in the CBD, was diagnosed. Non per oral diet, intravenous hydration, pain killers, and antibiotics (cefotaxime and metroni-
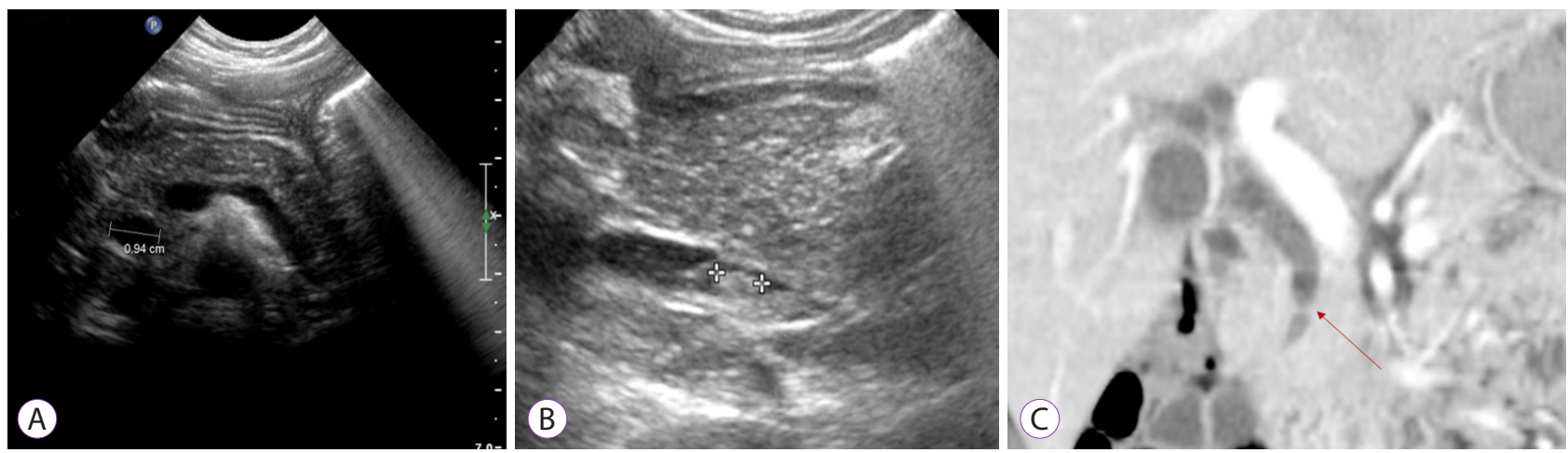

Fig. 1. Abdominal radiologic studies show the dilated intrahepatic and common bile duct (CBD) with $0.94 \mathrm{~cm}$ in diameter (A), and a 4.7-mm-sized echogenic material in the distal $\mathrm{CBD}(\mathrm{B})$ on abdominal ultrasonography. Pancreaticobiliary computed tomography reveals a web-like structure (arrow) in the CBD (C).
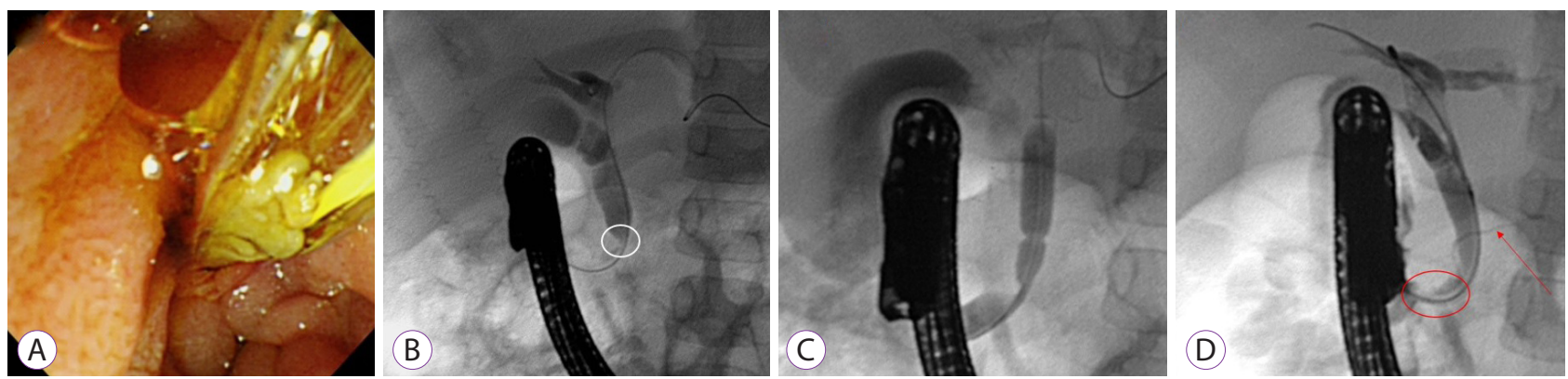

Fig. 2. Squashed muddy stone from the common bile duct $(C B D)$ is extracted by endoscopic balloon dilation $(A)$. Endoscopic retrograde cholangiography shows dilated proximal bile ducts and a narrowing and a shelf-like linear contrast shadow (white circle) in the distal CBD (B). Balloon dilation of the bile duct is performed to dilate the orifice and stricture of the $\mathrm{CBD}(\mathrm{C})$. Cholangiography after CBD dilatation shows dilated stricture and a common channel (red circle) with the pancreatic duct (red arrow, D). Abnormal pancreaticobiliary junction is noted. 

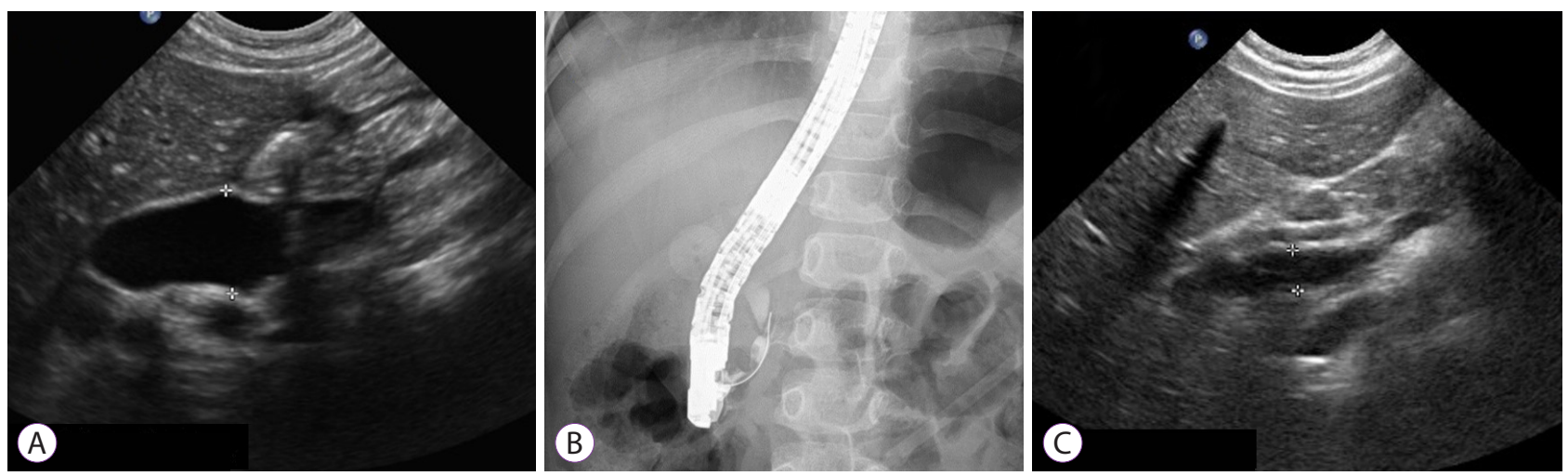

Fig. 3. Marked dilated intrahepatic and extrahepatic duct $(1.63 \mathrm{~cm}$ in diameter) is shown on abdominal ultrasonography, when the patient was re-admitted (A). Endoscopic retrograde cholangiography shows a tight stricture and filling defects in the common bile duct (B). After recanalization, the dilated extrahepatic duct is improved to $0.67 \mathrm{~cm}$ in diameter $(\mathrm{C})$.

dazole) were started. We decided to perform ERCP to evaluate and manage the stones and septum in the CBD. Endoscopic procedure was performed on the 6th day of admission under general anesthesia when the serum amylase and lipase levels decreased to $75 \mathrm{U} / \mathrm{L}$ and $32 \mathrm{mg} / \mathrm{dL}$, respectively. A squashed muddy stone was extracted from the CBD (Fig. 2A). A thin narrowing and a shelf-like linear contrast shadow in the distal CBD as well as proximal bile duct dilatation were observed on ERCP (Fig. 2B). The CBD patency was re-established by balloon dilation (Fig. 2C), and an abnormal pancreaticobiliary junction of the common channel was suspected (Fig. 2D). Post-ERCP pancreatitis occurred, and the serum amylase and lipase levels increased to $1,749 \mathrm{U} / \mathrm{L}$ and $>700 \mathrm{mg} / \mathrm{dL}$, respectively. Conservative treatment was started again. After regression of the post-ERCP pancreatitis, the patient was discharged in good general condition on the 15th day of hospitalization. After 11 months, the patient visited our hospital again due to pancreatitis and biliary tract dilation caused by distal CBD stricture, probably due to previously incomplete recanalization (Fig. 3A, B). ERCP with balloon dilation was performed, and the child was discharged on the 5th day of re-hospitalization with improvement of pancreatitis and distal CBD stricture (Fig. 3C). She has been doing well for 4 years since then.

\section{DISCUSSION}

CBD web is caused by congenital malformation and acquired inflammation due to recurrent stones or injury, but it is uncommon. To date, a number of CBD web cases in adults has been reported worldwide; however, a pediatric case of congenital CBD web is rare. ${ }^{1,4,10-13}$ Acquired CBD web is caused by injury during biliary procedure or surgery, chronic inflammation due to recurrent stones, and malignancy. ${ }^{2,13}$ Congenital
CBD web, on the other hand, is caused by incomplete biliary tract recanalization during embryogenesis, ${ }^{12}$ and it is often accompanied by a choledochal cyst, hepatic fibrosis, and anomalous junction of the pancreaticobiliary ductal system. ${ }^{4,12}$ In our patient, $\mathrm{CBD}$ stricture may be congenital rather than acquired because she is young and previously healthy, and surgery or trauma is absent. In addition, the external CBD shape is preserved, and the concomitant muddy and soft CBD stone may not cause biliary tract irritation.

$\mathrm{CBD}$ web can present at any age depending on the degree of ductal patency for bile flow, ${ }^{4,12}$ although it is usually asymptomatic. CBD web may lead to obstructive jaundice associated with cholangitis or cholelithiasis. ${ }^{4}$ In the patient, acute pancreatitis was presented rather than obstructive jaundice, which might have been caused by the associated pancreaticobiliary maljunction. Biliary flow might be relatively preserved because of the incomplete CBD obstruction by the web and muddy stone. Although the CBD stone and web did not cause obstructive jaundice in the patient, they caused hepatocellular and canalicular injuries judging from the elevated AST, ALT, and GGT on the chemical analyses.

The CBD web diagnosis is challenging because it is often asymptomatic and detected by chance during ERCP or surgery. ${ }^{10}$ Sometimes, excessive contrast media injection into the biliary tract during ERCP can result in an image similar to that of the CBD web; however, it is usually resolved by timely spontaneous excretion. ${ }^{11}$ Abdominal USG or CT can easily detect the dilated bile ducts; however, it is challenging to detect any membranous structure in the biliary ducts. ${ }^{12}$ In the patient, the stones and the dilated biliary tract were detected on abdominal USG and CT, and the coronal view of pancreaticobiliary CT suggested a membranous structure in the CBD (Fig. 1C).

Surgical resection is the treatment of choice in CBD web with cholestasis or cholangitis. ${ }^{11}$ However, successful endo- 
scopic balloon dilation and stent insertion in adults has been reported in Korea. ${ }^{10,14}$ Endoscopic treatment can be considered in a case of incomplete or mild form of obstruction, ${ }^{12}$ and ERCP in the pediatric population is considered as a safe and efficient diagnostic and therapeutic modality in PBD. ${ }^{6,9,15}$ In our case, the endoscopic approach was considered for the treatment of CBD stone and web after acute pancreatitis regression. Endoscopic CBD stone removal and balloon dilation of the $\mathrm{CBD}$ web were successfully performed. After re-establishing the CBD patency, a common biliary channel with the pancreatic duct was noted on cholangiography (Fig. 2D).

ERCP-related pancreatitis is not uncommon. ${ }^{3}$ Unfortunately, pancreatitis occurred after ERCP in the patient, which was caused by pancreaticobiliary maljunction, previous pancreatitis, and ERCP itself.

CBD stone is rare in children, although it has become more common nowadays. Most of the stones in children are black pigment or cholesterol stones and usually originate from the gall bladder (GB). ${ }^{16}$ In the patient, an isolated CBD stone without gallstone was detected, and it was soft, greasy, and bright yellow. Based on the clinical information, the CBD stone was caused by the CBD web and the pancreaticobiliary junctional abnormality. Hemolysis or the use of drugs, such as ceftriaxone, was not noted. Since the incidence of GB stone in adults is relatively high, although wide variations among racial and ethnic groups exist, ${ }^{16}$ genetic background for the CBD stone in this patient is less likely, despite the mother having an asymptomatic GB stone. The CBD web and stone have been endoscopically removed, but the patient still has a risk for CBD stone formation and pancreatitis occurrence owing to her pancreaticobiliary junctional abnormality. Therefore, regular and serial check-ups are warranted.

Previously, a congenital CBD web associated with hepatobiliary pancreatic ductal anomalies in an 8-year-old boy was reported in India. However, to the best of our knowledge, a congenital CBD web case in early childhood successfully treated by balloon dilation under ERCP has not been reported. ${ }^{17}$ Although it is rare, congenital CBD web could be one of the differential diagnoses of choledocholithiasis and acute pancreatitis in children.

Conflicts of Interest

The authors have no potential conflicts of interest.

$$
\begin{gathered}
\text { Funding } \\
\text { None. }
\end{gathered}
$$

Author Contributions

Conceptualization: Ji Sook Park, Ji-Hyun Seo

Data curation: JSP, Hong Jun Kim

Formal analysis: JSP

Methodology: HJK
Resources: JHS

Supervision: JHS

Validation: $\mathrm{HJK}$

Writing-original draft: JSP

Writing-review\&editing: JHS, Hee-Shang Youn

\section{ORCID}

Ji Sook Park:

Hong Jun Kim:

Ji-Hyun Seo:

Hee-Shang Youn: https://orcid.org/0000-0002-4704-2246 https://orcid.org/0000-0002-0411-668X https://orcid.org/0000-0002-0691-3957 https://orcid.org/0000-0002-5498-838X

\section{REFERENCES}

1. Cho H-J, Kim K-S, Kim G-H. Biliary web: a rare cause of extrahepatic biliary obstruction. Ann Surg Treat Res 2004;66:519-522.

2. Krishna RP, Lal R, Sikora SS, Yachha SK, Pal L. Unusual causes of extrahepatic biliary obstruction in children: a case series with review of literature. Pediatr Surg Int 2008;24:183-190.

3. Cheng CL, Fogel EL, Sherman S, et al. Diagnostic and therapeutic endoscopic retrograde cholangiopancreatography in children: a large series report. J Pediatr Gastroenterol Nutr 2005;41:445-453.

4. Margolis M, Schein M. Biliary web--a rare cause of extrahepatic biliary obstruction. Dig Surg 2001;18:317-319.

5. Enestvedt BK, Tofani C, Lee DY, et al. Endoscopic retrograde cholangiopancreatography in the pediatric population is safe and efficacious. J Pediatr Gastroenterol Nutr 2013;57:649-654.

6. Halvorson L, Halsey K, Darwin P, Goldberg E. The safety and efficacy of therapeutic ERCP in the pediatric population performed by adult gastroenterologists. Dig Dis Sci 2013;58:3611-3619.

7. Jang JY, Yoon $\mathrm{CH}$, Kim KM. Endoscopic retrograde cholangiopancreatography in pancreatic and biliary tract disease in Korean children. World J Gastroenterol 2010;16:490-495.

8. Osanai M, Maguchi H, Takahashi K, et al. Safety and long-term outcomes of endoscopic papillary balloon dilation in children with bile duct stones. Gastrointest Endosc 2011;73:619-623.

9. Paris C, Bejjani J, Beaunoyer M, Ouimet A. Endoscopic retrograde cholangiopancreatography is useful and safe in children. J Pediatr Surg 2010;45:938-942.

10. Baek SM, Kim DU, Jang SM, et al. [A common bile duct web in association with bile duct stone treated with balloon dilatation]. Korean J Pancreas Biliary Tract 2014;19:147-151.

11. Baek SH, Cheon YK, Cho YD, Lee JS, Shim CS, Kim BS. [A common bile duct web in association with common bile duct stone]. Korean J Gastroenterol 2005;46:306-309.

12. Papaziogas B, Lazaridis C, Pavlidis T, Galanis I, Paraskevas G, Papaziogas T. Congenital web of the common bile duct in association with cholelithiasis. J Hepatobiliary Pancreat Surg 2002;9:271-273.

13. Ra DJ, Choi JD, Lee MS, Kim JH, Cho SW, Shim CS. 4 cases of web of common bile duct. Korean J Gastrointest Endosc 1992;12:81-86.

14. Im Y-S, Chung W-C, Lee K-M, et al. A case of the common bile duct web treated with a retrievable covered metallic stent. Korean J Gastrointest Endosc 2008;36:181-186.

15. Hiramatsu T, Itoh A, Kawashima H, et al. Usefulness and safety of endoscopic retrograde cholangiopancreatography in children with pancreaticobiliary maljunction. J Pediatr Surg 2015;50:377-381.

16. Fishman DS, Gilger MA. Diseases of the gallbladder. In: Wyllie R, Hyams JS, eds. Pediatric gastrointestinal and liver disease. 4th ed. Philadelphia (PA): Saunders; 2011. p. 866-876.e4.

17. Shera AH, Shah OJ. Congenital common bile duct web in association with hepatobiliary pancreatic ductal anomalies. Eur J Pediatr Surg 2008;18:350-351 